\title{
PROACTIVE CAR PARKING SYSTEM USING IOT
}

\author{
Dr. B. Gomathi* \\ Assistant Professor \\ Department of Computer Science \\ Shri Shankarlal Sundarbai Shasun Jain College for Women \\ Chennai, Tamilnadu, India. \\ Email: gomathiphd2k15@gmail.com
}

\begin{abstract}
Every City in India as well as other countries are moving towards the concept of Smart Cities. Increase in population is directly proportional to the increase in traffic and almost all cities are densely populated. This paper provides a novel approach of identifying the vehicles and appropriately redirecting them to parking slots This Proactive Car Parking System framework encompasses IOT module that is applied to screen and signalize the condition of accessibility of single parking spot. In addition to this it signals in case of empty slot and hence the driver of the vehicle need not waste time in searching the slot. The status on availability of parking is informed in advance and this in turn helps to avoid traffic. The IR sensor with Arduino is used for identifying slots. The proposed system is an embedded system where internet, Sensors, detection of objects and algorithms are used.
\end{abstract}

Keywords: IOT, RFID, Arduino, GSM Module, IR Sensor, cloud database 


\section{Introduction}

In current scenario IOT plays vital role in almost all areas right from smart homes to Smart Cities. Traffic control is one of the key area where IOT can play a vital role. The major problem faced in malls and hospitals is finding a parking slot to park the vehicles. During peak hours finding parking space is the most difficult task. Parking garage problem is basically locating unfilled slot in case of both multilevel or single level garage [1]. During weekends shopping malls, stadium and hotels find very difficult to accommodate vehicles. Another key factor to be taken into consideration is smart parking system is unfilled slots and the procedures to proactively inform the slots.[2].Nowadays instant loans are provided by banks and as per survey by 2035[3] increase in vehicle population will be around 1.7 billion. Another survey suggests that one million barrel of worlds fuel is being utilized each day.[4]. The proposed system is arranged in a phased manner, In the first phase using IR sensor and Arduino parking slot are identified. In the second phase cloud services are used to inform the user and interact with the parking area. This is updated to see that current status of parking slot is maintained. Users can view the availability while admin has entire rights on the service provided. In third phase user gets notifications on available slot via SMS through GSM. This facility of notification makes the user think proactively and take decision without wasting time and fuel.It consists of three parts where first part is the parking area which include Arduino devices as well as parking area. The user gets the notification when the parking availability is full which saves the time and fuel thus benefiting user and nation.

\section{Literature Review}

RFID is generally used in the main entrance of parking [1]. The author mentions that availability is known only when the driver reaches the main entrance and hence, smart actions cannot be taken by the driver. The author Al-Kharusi [5] suggest parking based on image using video sensors. Cloud services are used by the author Abhirup Khanna [6] for smart parking system. Image processing technique is also utilised in identification and a brown colour circle is drawn to identify empty and filled slots.[7].Cloud system is used by the author Lotlikar Et.al[8] and the paper also presents disadvantages relating to sensors, control and management. . Barriga, J.J. et al.[9] thoroughly presented a review on various methodologies used in smart parking system. The advantages and disadvantages were well illustrated in the paper. Detecting the number plate using computer vision is dealt by author Rachapol Lookmuang,[10]. Reservation of parking is dealt in the paper and the user can pay in advance too. . J. Cynthia, C. B. (2018) [11]in the paper suggested ways to identify nearest parking based on size of the vehicle apart from reservation and pay as you go service. 


\section{Proposed System Architecture}

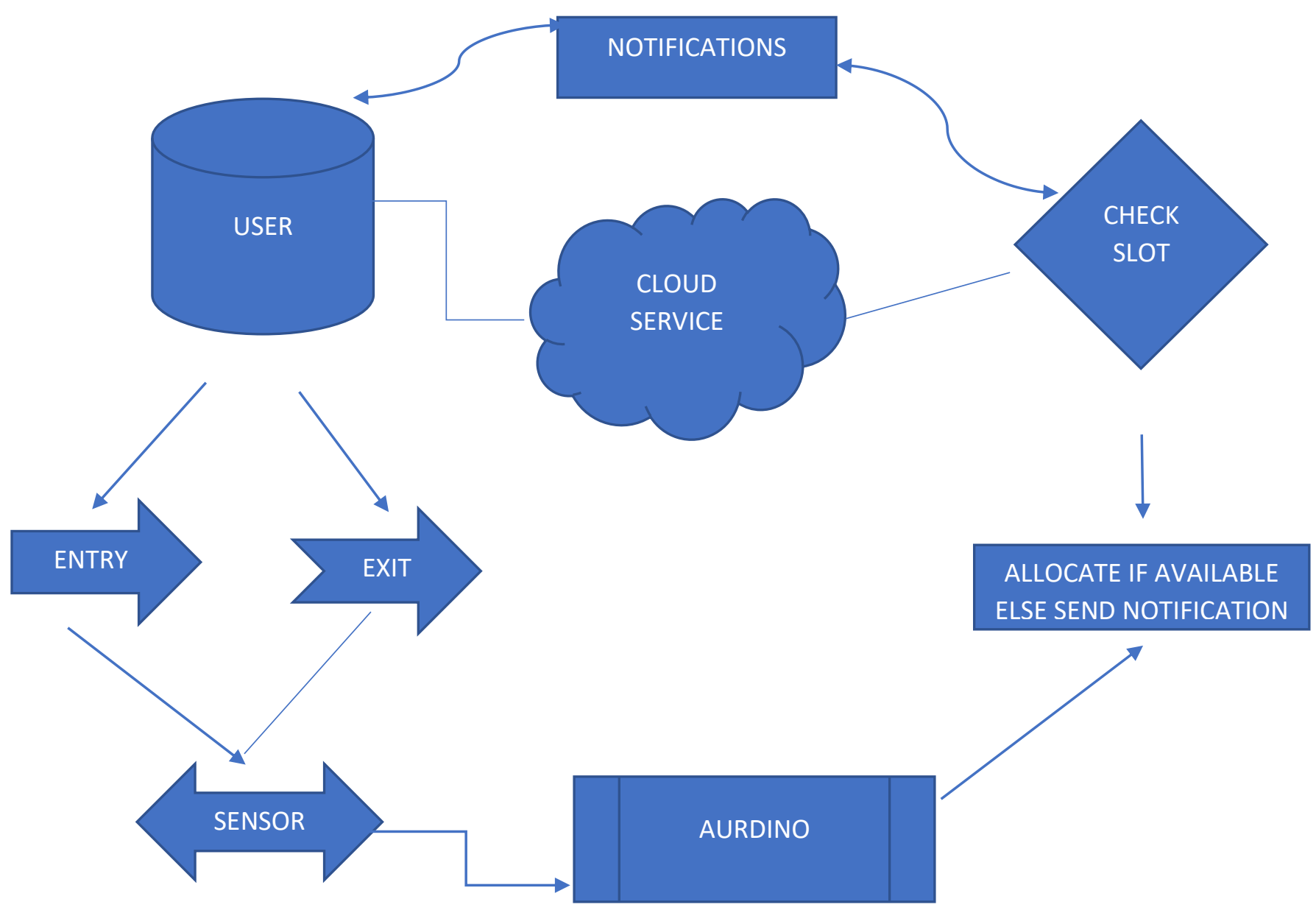

Figure 1: Proposed System Architecture

\subsection{Hardware components}

The below Table 1 represents the hardware components utilised in our proposed system. 
Table 1 Description of Hardware components.

\begin{tabular}{|l|l|}
\hline Component Name & Description \\
\hline Arduino Uno & $\begin{array}{l}\text { It is Micro controller board with } 14 \\
\text { pins for input and output }\end{array}$ \\
\hline IR Sensor & These are diodes with 2 terminals \\
\hline Servo Motor & A rotator device \\
\hline LCD Display & A flat panel display screen \\
\hline RFID CARD & Information about Registered user \\
\hline
\end{tabular}

\subsubsection{Arduino Uno}

It is a microcontroller board, with 14 pins of which 6 can be used as PWM outputs, 6 analog inputs, a $16 \mathrm{MHz}$ quartz crystal, a USB connection, a power jack, an ICSP header and a reset button in short it contains everything needed to support the microcontroller.

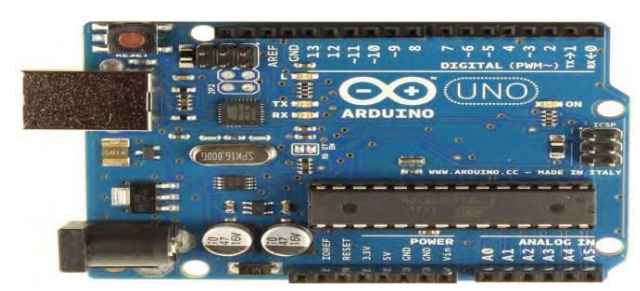

Figure 2: Arduino R3 Board

\subsubsection{IR Sensor}

It is basically used for detection of objects. This works on the principle of light that is if light is detected then object is present and if light is not detected then object is not present.

\subsubsection{RFID}

Here radio waves are used for identification, and when RFID is used apart from identification tracking of the devices can also be done.

\subsection{Software Description}

Cloud server plays active role as mediator. The server is connected to Wi-Fi and hence the user receives SMS on every entry and exit of the parking area with the help of RFID. Without RFID card users are not allowed inside the parking. When the IR detects the car SMS is triggered using cloud service and this is updated on every entry and exit. 


\section{Implementation}

The procedure followed for implementation is when the user enters the parking area his RFID card is scanned using scanner. If the user does not have card he is not allowed in the area due to security reasons. Once user is identified IR sensor detects the object and checks for availability of slots and triggers SMS using cloud services. The cloud status is updated on every entry and exit.

Steps in Implementation

1. Scan the RFID card

2. Authenticate the User

3. IR sensor detects the object

4. SMS is triggered

5. Status updated on every entry and Exit.

\section{USER AUTHENTICATION}

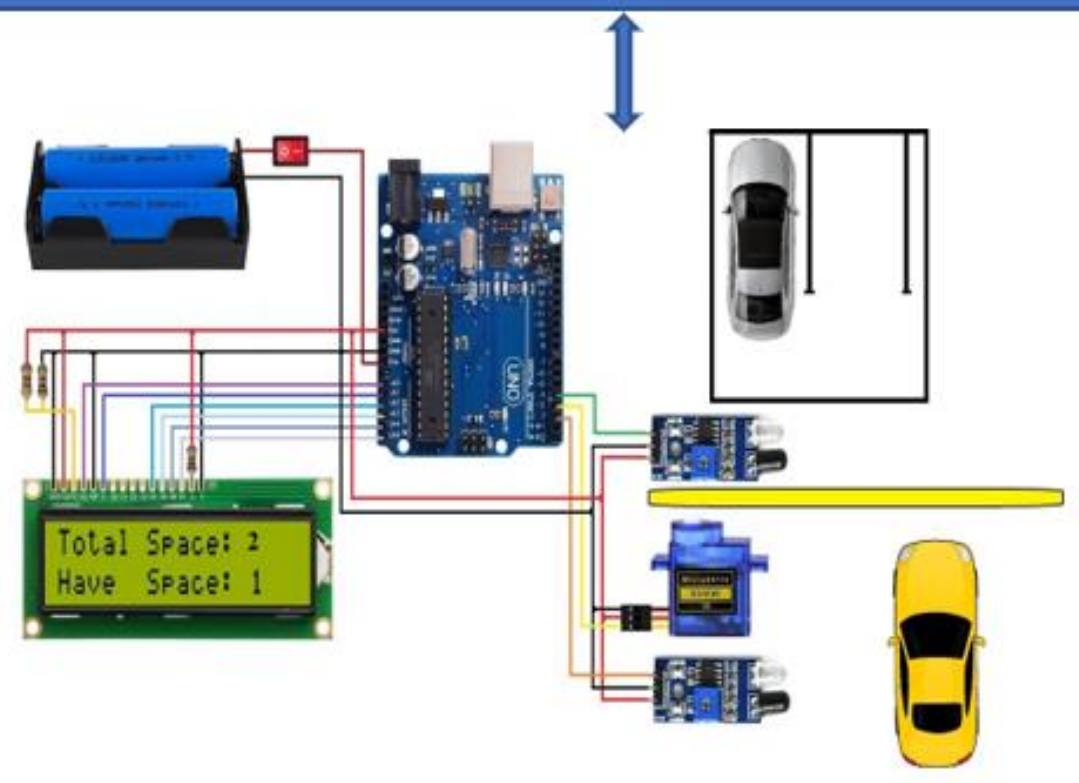

Figure 3: Block Diagram

The three major components used in our method are Arduino Uno R3, Module and IR Module. Coding is done using Arduino IDE Programming language. The display on the slot availability is given in the LCD. 


\section{Pseudocode for Slot allocation}

Begin

Initialise

Total slot=n;

Update

Busy

Slot=a;

After every

entry:

Increment $\mathrm{a}=\mathrm{a}+1$;

\section{Calcuate Free $\mathrm{S}$}

\section{End}

After slot allocation the WIFI module sends data from embedded system using TCP/IP. It is a 32 bit controller with 16 pins. If the slot is available it sends a message regarding availability else notification on non-availability is also triggered to the user. The below diagram shows the messages received by the used.

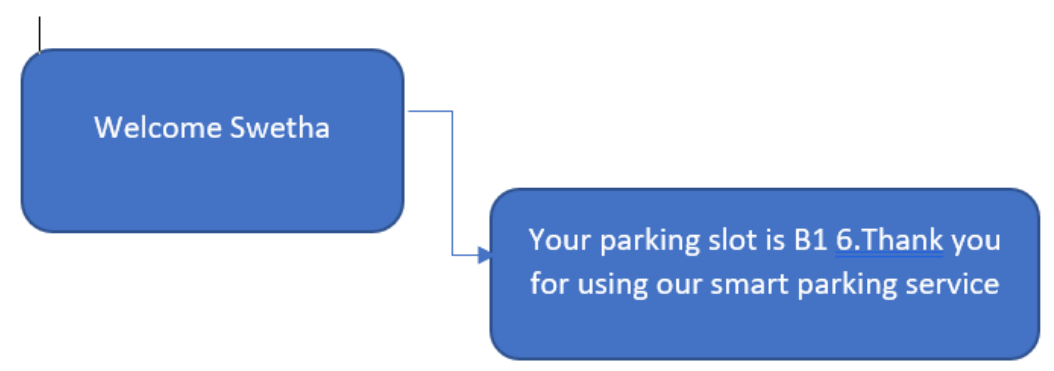

Figure 4: User Message

\section{Results and Conclusion}

This paper not only provides scope for smart parking but also security of car is also maintained. The users get information through SMS and they can act proactively without wasting time in searching parking slot as well avoid wasting fuel. The increase in population leads to increase in vehicle and hence smart parking system helps to avoid last minute rush and waits. It also helps to control traffic as slot availability is updated on every entry and exit and user are notified. In future we can consider on finding our nearest parking space and also link with payments so that user can reserve by making prior payments. UV sensors can also be utilized to increase the efficiency. 


\section{References:}

1. Nimble, J., Bhegade, P., Surve, S., \& Chaugule, P. (2016). Automatic Smart Car Parking System. International Journal of Advances in Electronics and Computer Science, Vol. 3(3), pp. 49-51, ISSN: 2393-2835.

2. Shree, B. (2017). Design and Implementation of Automated Car Parking System using RFID. International Journal of Advanced Research in Computer and Communication Engineering, Vol. 6(2), ISSN: 23195940.

3. Mohit Patil, R. S. (2014). Smart Parking System Based On Reservation. International Journal of Scientific Engineering and Research (IJSER), 6.

4. Khaoula Hassoune, W. D. (2016). Smart parking Systems:A Survey . IEEE, 6

5. Al-Kharusi, H. \& Al-Bahadly, I. (2014). Intelligent Parking Management System Based on Image processing. World Journal of Engineering and Technology, School of Engineering and Advanced Technology, Massey University, Palmerston North, New Zealand, Vol. 2, pp. 55-67.

6. Abhirup Khanna, R. A. (2016). IoT based Smart Parking System. International Conference on Internet of Things and Applications (IOTA) (p. 5). Pune: IEEE

7. Karthik, K.J., Kaur, S., Reddy, M.N. \& Rao Ch, U.M. (2017). Smart Parking Using Image Processing. International Journal for Research in Applied Science \& Engineering Technology (IJRASET). Vol 45. ISSN: 2321-9653

8. Lotlikar, T., Chandrahasan, M., Mahadik, A., Oke, M. \& Yeole, A. (2016). Smart Parking Application. International Journal of Computer Applications. Vol. 149(9).

9. Barriga, J.J. et al. (2019). Smart Parking: A Literature Review from the Technological Perspective. MDPI Journal of Applied Science. Vol 9, (4569). doi:10.3390/app9214569.

10. Rachapol Lookmuang, K. N. (2018). Smart Parking Using IoT Technology. IEEE, 6.

11. J. Cynthia, C. B. (2018). IOT based Smart Parking Management System. International Journal of Recent Technology and Engineering (IJRTE), 6 